\title{
Acúmulo de matéria seca e de nutrientes em forrageiras consorciadas com milho safrinha em função da adubação nitrogenada
}

\author{
Karina Batista(1), Aildson Pereira Duarte ${ }^{(2)}$, Gessi Cecconn ${ }^{(3)}$, Isabella Clerici De Maria ${ }^{(4)}$ e Heitor Cantarella ${ }^{(4)}$ \\ (1)Instituto de Zootecnia, Caixa Postal 60, CEP 13460-000 Nova Odessa, SP. E-mail: karina@iz.sp.gov.br (2)Agência Paulista de Tecnologia \\ dos Agronegócios, Pólo Médio Paranapanema, Rodovia SP 333 Assis-Marilía, Km 397, Caixa Postal 263, CEP $19800-000$ Assis, SP. \\ E-mail: aildson@apta.sp.gov.br ${ }^{(3)}$ Embrapa Agropecuária Oeste, Caixa Postal 661, CEP 79804-970 Dourados, MS. E-mail: gessi@cpao.embrapa.br \\ (4)Instituto Agronômico, Caixa Postal 28, CEP 13001-970 Campinas, SP. E-mail: icdmaria@iac.sp.gov.br, cantarella@iac.sp.gov.br
}

\begin{abstract}
Resumo - O objetivo deste trabalho foi avaliar o acúmulo de matéria seca e de nutrientes de plantas forrageiras consorciadas com o milho safrinha, em função da adubação nitrogenada. As espécies Urochloa brizantha cv. Marandu, U. decumbens cv. Basilisk, U. ruziziensis cv. Comum e Panicum maximum cv. Tanzânia, com semeadura em meados de março, foram avaliadas em quatro municípios paulistas, em consórcio com o milho. Utilizou-se o delineamento experimental de blocos ao acaso, com quatro repetições, em parcelas subdivididas. Nas parcelas, foram avaliados os consórcios e nas subparcelas, quatro doses de nitrogênio em cobertura $(0,30,60$ e $90 \mathrm{~kg} \mathrm{ha}^{-1}$ ). Foi determinado o acúmulo de matéria seca e de nutrientes pelas plantas forrageiras em três épocas: no florescimento, na maturidade fisiológica do milho e por ocasião da dessecação das forrageiras, em outubro. O acúmulo de matéria seca das forrageiras intensifica-se após a colheita do milho safrinha. Quando as forrageiras são semeadas na entrelinha do milho, a adubação nitrogenada em cobertura não interfere no acúmulo de matéria seca e de nutrientes pelas forrageiras, e o consórcio não afeta a produtividade de grãos de milho safrinha.
\end{abstract}

Termos para indexação: capim-braquiária, capim-marandu, capim-ruziziensis, capim-tanzânia, integração lavoura-pecuária.

\section{Dry matter and nutrient accumulation in forage plants intercropped with off-season maize as a function of nitrogen fertilization}

\begin{abstract}
The objective of this work was to assess the accumulation of dry matter and nutrients in forage plants intercropped with off-season maize, as a function of nitrogen fertilization. The species Urochloa brizantha cv. Marandu, U. decumbens cv. Basilisk, U. ruziziensis cv. Comum, and Panicum maximum cv. Tanzânia, with seeding in mid-March, were evaluated in four municipalities of São Paulo, Brazil, intercropped with maize. A randomized complete block design was used, with four replicates, in split-plots. The intercropped systems were evaluated in the plots, and four nitrogen topdressing fertilization rates $\left(0,30,60\right.$, and $\left.90 \mathrm{~kg} \mathrm{ha}^{-1}\right)$ were evaluated in the split-plots. Forage dry matter and nutrient accumulation were determined in three stages: flowering, maize physiological maturity, and at forage desiccation, in October. Forage dry matter accumulation increases after the harvest of off-season maize. When forages are planted in the corn inter-rows, topdressing nitrogen fertilization does not influence forage dry matter and nutrient accumulation, and intercropping does not affect off-season maize grain yield.
\end{abstract}

Index terms: signal-grass, marandu palisade-grass, Congo signal grass, Guinea grass, crop-livestock integration.

\section{Introdução}

Os sistemas de cultivo consorciado de lavouras de grãos com plantas forrageiras proporcionam o aumento da disponibilidade de forragem na estação seca, com qualidade suficiente para manutenção nutricional dos rebanhos e, até mesmo, para promoção de ganho de peso animal. Além disso, esses sistemas eliminam a necessidade de se semear plantas de cobertura no inverno ou na primavera, para a produção de palha para o plantio direto (Barducci et al., 2009).
Ceccon (2007) descreve um sistema consorciado em que a semeadura do milho safrinha é realizada com uma semeadora ajustada para soja, com uso de uma linha para semeadura de milho e outra linha para a espécie forrageira. Esse sistema possibilitou o aumento na produtividade das pastagens, em comparação ao uso de pastagens degradadas utilizadas durante o ano inteiro (Broch et al., 2007). Em sistemas consorciados com o milho, as plantas forrageiras diminuem a produção de folhas, colmos e bainhas, mas apresentam satisfatório 
potencial de rebrota e priorizam a produção de folhas após a colheita de grãos (Borghi et al., 2007).

O aproveitamento da adubação residual da cultura antecessora pela pastagem é um dos aspectos positivos do consórcio entre milho safrinha e plantas forrageiras (Broch et al., 2007). No milho safrinha cultivado após a cultura da soja, normalmente são aplicadas baixas doses de nitrogênio, cerca de 30 a $50 \mathrm{~kg} \mathrm{ha}^{-1}$, pois ocorre fixação biológica de nitrogênio pela leguminosa e há pouca chance de perdas de nitrato por lixiviação nas condições de cultivo da safrinha, em virtude do menor volume de chuvas no período (Duarte \& Cantarella, 2007). Entretanto, no cultivo consorciado, a demanda de nitrogênio pelas forrageiras pode ser maior, o que requer estudos mais aprofundados.

O objetivo deste trabalho foi avaliar o acúmulo de matéria seca e de nutrientes de plantas forrageiras consorciadas com o milho safrinha, em função da adubação nitrogenada.

\section{Material e Métodos}

Os experimentos foram conduzidos de fevereiro a outubro de 2008, em sistema de plantio direto, em áreas localizadas em: Campos Novos Paulista $\left(22^{\circ} 36^{\prime} \mathrm{S}\right.$, $50^{\circ} 00^{\prime} \mathrm{W}$, a $550 \mathrm{~m}$ de altitude), Florínea $\left(22^{\circ} 54^{\prime} \mathrm{S}, 50^{\circ} 44^{\prime} \mathrm{W}\right.$, a $360 \mathrm{~m}$ de altitude), Palmital (22 $42^{\circ} \mathrm{S}, 50^{\circ} 13^{\prime} \mathrm{W}$, a $508 \mathrm{~m}$ de altitude) e Pedrinhas Paulista $\left(22^{\circ} 29^{\prime} \mathrm{S}, 50^{\circ} 28^{\prime} \mathrm{W}\right.$, a $330 \mathrm{~m}$ de altitude), no Estado de São Paulo. O solo da região é classificado como Latossolo Vermelho férrico, conforme o Sistema Brasileiro de Classificação de Solos (Santos et al., 2006). O clima, segundo a classificação de Köppen, é do tipo Cwa, mesotérmico, de inverno seco, em transição para Cfa, mesotérmico e úmido, sem estiagem, de acordo com Brunini \& Prela (2007).

A semeadura dos consórcios ocorreu em: 14/3/2008, em Campos Novos Paulista; 18/3/2008, em Palmital; 26/3/2008, em Florínea; e3/4/2008, em Pedrinhas Paulista. Antes do período experimental, foi realizada amostragem do solo das áreas experimentais para caracterização química (Tabela 1).

Utilizou-se o delineamento experimental de blocos ao acaso, com quatro repetições, em parcelas subdivididas. Nas parcelas, foram avaliados cinco consórcios: milho+Urochloa brizantha cv. Marandu, milho+U. decumbens cv. Basilisk, milho+U. ruziziensis cv. Comum, milho+Panicum maximum cv. Tanzânia (forrageiras semeadas na entrelinha do milho), e milho $+U$. brizantha cv. Marandu semeada a lanço. Nos consórcios em que as forrageiras foram semeadas em cultivo intercalar, utilizou-se semeadora ajustada para soja (0,45 m entre linhas), com uso de uma linha para a semeadura do milho e outra linha para a espécie forrageira (Ceccon, 2007), exceto em Palmital, em que o espaçamento entre as plantas forrageiras e o milho foi de $0,30 \mathrm{~m}$. O tratamento testemunha consistiu do plantio de milho solteiro com espaçamento entre linhas de $0,90 \mathrm{~m}$. Nas subparcelas, foram testadas quatro doses de $\mathrm{N}$ em cobertura $\left(0,30,60\right.$ e $\left.90 \mathrm{~kg} \mathrm{ha}^{-1}\right)$, no estádio de duas a seis folhas do milho, tendo-se utilizado o nitrato de amônio como fonte de N. A distribuição das doses foi realizada manualmente na superfície do solo.

As parcelas foram compostas por oito linhas de $43 \mathrm{~m}$ de comprimento. As subparcelas tinham $10 \mathrm{~m}$ de comprimento, com 1,0 m de corredor nas extremidades. As linhas laterais foram consideradas como bordadura, e as linhas úteis foram constituídas de 7,0 $\mathrm{m}$ de cada uma das duas linhas centrais, onde foram realizadas as avaliações.

A cultivar de milho utilizada foi a DKB 390. $\mathrm{Na}$ adubação de semeadura do milho, utilizou-se $30 \mathrm{~kg} \mathrm{ha}^{-1}$ de N (Duarte \& Cantarella, 2007). A semeadura foi mecanizada, tendo-se distribuído cerca de cinco sementes por metro. Para a instalação dos consórcios, as plantas forrageiras foram semeadas simultaneamente ao milho, em caixa com disco de sorgo universal, de acordo com Ceccon (2007). A semeadura da forrageira a lanço foi feita manualmente, antes da semeadura do milho safrinha.

Tabela 1. Caracterização química do solo na camada de 0-0,20 m, em Campos Novos Paulista, Florínea, Palmital e Pedrinhas Paulista, Estado de São Paulo.

\begin{tabular}{|c|c|c|c|c|c|c|c|c|c|c|c|}
\hline Local & $\begin{array}{c}\mathrm{pH} \\
\mathrm{em} \mathrm{CaCl}_{2}\end{array}$ & $\begin{array}{c}\mathrm{MO} \\
\left(\mathrm{g} \mathrm{dm}^{-3}\right)\end{array}$ & $\begin{array}{c}\mathrm{P} \\
\left(\mathrm{mg} \mathrm{dm}^{-3}\right) \\
\end{array}$ & K & $\mathrm{Ca}$ & $\mathrm{Mg}$ & $\begin{array}{c}\mathrm{H}+\mathrm{Al} \\
\mathrm{mol}_{\mathrm{c}} \mathrm{dn}\end{array}$ & S & SB & CTC & $\begin{array}{c}\mathrm{V} \\
(\%)\end{array}$ \\
\hline Campos Novos Paulista & 5,1 & 27 & 11 & 3,7 & 31 & 11 & 28 & 6 & 45,7 & 73,5 & 62 \\
\hline Florínea & 5,2 & 27 & 24 & 1,4 & 33 & 14 & 31 & 3 & 48,4 & 79,2 & 61 \\
\hline Palmital & 4,6 & 27 & 23 & 2,7 & 17 & 4 & 52 & 28 & 23,7 & 75,9 & 31 \\
\hline Pedrinhas Paulista & 5,1 & 24 & 54 & 6,3 & 41 & 11 & 31 & 11 & 58,3 & 89,1 & 65 \\
\hline
\end{tabular}


A densidade de semeadura das forrageiras foi de $9 \mathrm{~kg} \mathrm{ha}^{-1}$ de sementes de braquiárias e de $6 \mathrm{~kg} \mathrm{ha}^{-1}$ de sementes de $P$. maximum, com valor cultural em torno de $32 \%$. Como as plantas forrageiras foram implantadas em época com restrição ao desenvolvimento vegetal, em virtude das baixas temperaturas e da pouca disponibilidade de água, não houve necessidade do uso de herbicidas para a supressão de seu desenvolvimento, conforme indicado por Ceccon (2007).

Quando os grãos apresentavam umidade inferior a $25 \%$, procedeu-se à colheita do milho, para avaliação da produtividade. Após a colheita, as forrageiras cresceram livremente até a dessecação, realizada em outubro de 2008. A quantificação do acúmulo de matéria seca das plantas forrageiras foi realizada nos estádios de florescimento e maturidade fisiológica do milho safrinha e por ocasião da dessecação das plantas forrageiras, antes da semeadura da soja. $\mathrm{O}$ acúmulo de nutrientes nas forrageiras foi avaliado apenas na maturidade fisiológica do milho e por ocasião da dessecação das plantas forrageiras. A amostragem para a quantificação do acúmulo de nutrientes foi realizada com a coleta de 1,0 m, em linha, de capim, sempre entre a terceira e a quarta linha de plantio do milho. As amostragens foram realizadas em locais distantes um do outro, para que o crescimento do capim não fosse beneficiado pela ausência de plantas no local da coleta anterior. As concentrações de N, P, K, Ca, Mg e S foram determinadas conforme a metodologia descrita por Bataglia et al. (1978).

Os resultados foram submetidos à análise de variância, e as médias foram comparadas pelo teste de Tukey, a $5 \%$ de probabilidade, com uso do SAS (SAS Institute, 1996). Para avaliação dos efeitos das doses de N, utilizou-se regressões polinomiais. Foi realizada análise conjunta dos dados.

\section{Resultados e Discussão}

A quantidade de matéria seca produzida pelas forrageiras diferiu significativamente entre os tratamentos, em todas as épocas de amostragem, exceto na maturação fisiológica do milho, em Pedrinhas Paulista (Tabela 2). No geral, houve menor produção de matéria seca no tratamento com capim-marandu a lanço e aumento expressivo da matéria seca entre os períodos avaliados. Ao se considerar todos os tratamentos e os locais, o valor médio de massa de matéria seca das forrageiras foi de $327 \mathrm{~kg} \mathrm{ha}^{-1}$, no florescimento do milho; de $842 \mathrm{~kg} \mathrm{ha}^{-1}$, na maturidade fisiológica; e de $1.878 \mathrm{~kg} \mathrm{ha}^{-1}$, na dessecação antes do plantio da soja. Portanto, a massa de matéria seca aumentou 5,7 vezes entre a primeira e a última amostragem.

Houve variação da resposta dos tratamentos entre os locais, provavelmente em decorrência das condições edafoclimáticas na implantação e no desenvolvimento das forrageiras. Por ocasião da dessecação dos capins, em Campos Novos Paulista e em Palmital, o capim-tanzânia apresentou a maior produção de matéria seca, tendo diferido do capim-marandu distribuído a lanço (Tabela 2). Entretanto, esse último tratamento esteve entre os de melhor desempenho, em Florínea e Pedrinhas Paulista.

O acúmulo de forragem pode ser explicado pelo balanço entre o aparecimento de tecidos foliares novos - crescimento bruto - e a senescência e a decomposição de tecidos mais velhos (Hodgson, 1990). O acúmulo de forragem observado entre a maturidade fisiológica do milho e a dessecação foi pronunciado. Em todos os casos, a massa de matéria seca das forrageiras, por ocasião da dessecação, dobrou em comparação à observada na maturidade fisiológica do milho, mesmo em período de baixa precipitação e baixas temperaturas. Na literatura, os dados de acúmulo de matéria seca geralmente se referem a períodos mais quentes e úmidos, com valores de produção de matéria seca superiores aos observados no presente trabalho. Kluthcouski \& Aidar (2003), ao estudar o consórcio de plantas forrageiras e diversas culturas anuais, relataram baixa produção de forragem de capim-marandu, na época de colheita da cultura anual (safra verão), mas um rápido desenvolvimento da forrageira após o início da senescência do milho. Os autores observaram acréscimos de 4.800 a $8.000 \mathrm{~kg} \mathrm{ha}^{-1}$, dependendo do local, na produção de silagem de capim-marandu, após a maturidade fisiológica do milho cultivado no verão.

Os resultados obtidos no presente trabalho confirmam a habilidade das plantas forrageiras em crescer, mesmo em condições de déficit hídrico e baixas temperaturas. De acordo com Barducci et al. (2009), U. brizantha e espécies do gênero Panicum, por terem sistema radicular vigoroso e profundo, apresentam elevada tolerância à deficiência hídrica e boa absorção de nutrientes em camadas mais profundas do solo. Esses fatores possibilitam que essas espécies se desenvolvam em condições ambientais em que a maioria das culturas produtoras de grãos e das espécies utilizadas para a cobertura do solo não se desenvolveriam. Contudo, a entrada 
de luz durante a colheita do milho e as primeiras chuvas ainda são essenciais para que ocorra um crescimento vigoroso das plantas.

Em Campos Novos Paulista, Florínea e Pedrinhas Paulista, a produção de matéria seca não respondeu significativamente às doses de $\mathrm{N}$ em cobertura, em nenhuma das épocas de amostragem. $\mathrm{O}$ pequeno desenvolvimento das forrageiras por ocasião da adubação de cobertura pode ter diminuído a capacidade dessas plantas em se beneficiar da adubação nitrogenada. Os resultados observados no presente trabalho estão de acordo com os obtidos por Borghi \& Cruciol (2007) que, ao avaliar modalidades de consórcio e espaçamentos entre milho e capim-marandu, plantados no verão, concluíram não haver comprometimento na absorção de $\mathrm{N}$ por nenhuma das culturas.

Em Palmital, a produção de matéria seca das forrageiras, no florescimento do milho, respondeu à adubação nitrogenada (Figura 1). De acordo com a equação de regressão obtida, a dose de $\mathrm{N}$ de $37 \mathrm{~kg} \mathrm{ha}^{-1}$ apresentou a maior produção de matéria seca. Esse resultado provavelmente está relacionado à distância entre as plantas, já que, em Palmital, as plantas forrageiras estavam localizadas mais próximas das plantas de milho, isto é, a $0,30 \mathrm{~m}$ ao invés de a $0,45 \mathrm{~m}$. Neste mesmo local, também foi observada interação significativa entre a forrageira e as doses de $\mathrm{N}$ aplicadas em cobertura. $\mathrm{O}$ acúmulo de matéria seca do capim-tanzânia e do capim-braquiária respondeu significativamente à adubação nitrogenada. A dose da maior produção de matéria seca do capim-tanzânia foi de $42 \mathrm{~kg} \mathrm{ha}^{-1}$ de $\mathrm{N}\left[\mathrm{y}=432,1951+10,8406 \mathrm{x}-0,1286 \mathrm{x}^{2}\right.$ $\left(\mathrm{R}^{2}=0,99\right)$ ], no florescimento. Na dessecação dos capins para o plantio da soja, o capim-braquiária respondeu linearmente às doses de $\mathrm{N}$ em cobertura $\left[y=708,6296+9,6280 x\left(R^{2}=0,66\right)\right]$, com variação no acúmulo de matéria seca entre 708,6 e $1.575 \mathrm{~kg} \mathrm{ha}^{-1}$. Os fatores ambientais podem interferir na resposta dessas espécies forrageiras ao $\mathrm{N}$, pois influenciam o tamanho das folhas e a densidade dos perfilhos, bem como o alongamento, a senescência e as taxas de aparecimento foliar (Chapman \& Lamaire, 1993).

$\mathrm{O}$ acúmulo de nutrientes $(\mathrm{N}, \mathrm{P}, \mathrm{K}, \mathrm{Ca}, \mathrm{Mg}$ e $\mathrm{S}$ ) na matéria seca das plantas forrageiras, por ocasião da maturidade fisiológica do milho safrinha e da dessecação para o plantio da soja, não apresentou respostas significativas às doses de adubação nitrogenada aplicadas na cobertura do milho safrinha, em todas as áreas experimentais. Em Campos Novos Paulista, na maturidade fisológica do milho safrinha, houve interação significativa entre o consórcio e as doses de $\mathrm{N}$ para o acúmulo de $\mathrm{K}, \mathrm{Ca}$ e $\mathrm{Mg}$.

$\mathrm{O}$ consórcio milho safrinha e capim-marandu distribuído a lanço apresentou os menores valores médios de acúmulo de nutrientes nas plantas forrageiras, em Campos Novos Paulista, por ocasião da maturidade fisiológica do milho (Tabela 3). De acordo com Boer et al. (2007), a quantidade de nutrientes acumulada depende da espécie utilizada, do estádio fenológico, da produção de matéria seca e do período de plantio. Neste mesmo local, houve menor acúmulo de matéria seca no tratamento com capim-marandu distribuído a lanço (Tabela 2). Esse menor acúmulo de matéria seca e de nutrientes no tratamento a lanço pode ser explicado pela concentração de plantas em locais distintos da área, com formação de touceiras localizadas. Quando o capim-marandu foi distribuído na entrelinha, as plantas foram distribuídas uniformemente pela área, o que teria possibilitado a exploração de um maior volume de solo.

Tabela 2. Acúmulo de matéria seca $\left(\mathrm{kg} \mathrm{ha}^{-1}\right)$ de plantas forrageiras consorciadas com milho safrinha em Campos Novos Paulista, Palmital, Florínea, e Pedrinhas Paulista, Estado de São Paulo, durante o florescimento (F) e a maturidade fisiológica do milho (M), e por ocasião da dessecação das forrageiras (D) ${ }^{(1)}$.

\begin{tabular}{|c|c|c|c|c|c|c|c|c|c|c|c|c|}
\hline \multirow[t]{2}{*}{ Consórcio } & \multicolumn{3}{|c|}{ Campos Novos Paulista } & \multicolumn{3}{|c|}{ Palmital } & \multicolumn{3}{|c|}{ Florínea } & \multicolumn{3}{|c|}{ Pedrinhas Paulista } \\
\hline & $\mathrm{F}$ & M & $\mathrm{D}$ & $\mathrm{F}$ & M & $\mathrm{D}$ & $\mathrm{F}$ & M & $\mathrm{D}$ & $\mathrm{F}$ & $\mathrm{M}$ & $\mathrm{D}$ \\
\hline Capim-ruziziensis & $394 \mathrm{ab}$ & $1.033 \mathrm{a}$ & $1.953 \mathrm{~b}$ & $631 \mathrm{a}$ & $1.298 \mathrm{a}$ & $2.352 \mathrm{ab}$ & $205 a$ & $590 \mathrm{bc}$ & $1.081 \mathrm{ab}$ & $378 \mathrm{ab}$ & $688 \mathrm{a}$ & $1.372 \mathrm{ab}$ \\
\hline Capim-marandu & $393 \mathrm{ab}$ & $1.185 \mathrm{a}$ & $2.672 \mathrm{ab}$ & $385 b c$ & $1.104 \mathrm{a}$ & $2.266 \mathrm{ab}$ & $127 \mathrm{~b}$ & $727 \mathrm{ab}$ & $905 b$ & $268 \mathrm{ab}$ & $789 a$ & $1.592 \mathrm{ab}$ \\
\hline Capim-tanzânia & $540 \mathrm{a}$ & $1.169 \mathrm{a}$ & $3.396 \mathrm{a}$ & $515 \mathrm{ab}$ & $1.094 \mathrm{a}$ & $3.858 \mathrm{a}$ & $147 \mathrm{ab}$ & $329 c$ & $1.043 \mathrm{ab}$ & $68 c$ & $520 \mathrm{a}$ & $1.234 b$ \\
\hline Capim-braquiária & $590 \mathrm{a}$ & $1.091 \mathrm{a}$ & $2.184 \mathrm{ab}$ & $470 \mathrm{ab}$ & $1.178 \mathrm{a}$ & $2.284 \mathrm{ab}$ & $110 \mathrm{~b}$ & $1.008 \mathrm{a}$ & $974 \mathrm{ab}$ & $234 b c$ & $626 a$ & $1.840 \mathrm{a}$ \\
\hline Capim-marandu a lanço & $274 b$ & $587 \mathrm{~b}$ & $1.996 b$ & $216 \mathrm{c}$ & $372 b$ & $1.481 \mathrm{~b}$ & $152 \mathrm{ab}$ & $365 \mathrm{c}$ & $1.375 \mathrm{a}$ & $440 \mathrm{a}$ & $1.080 \mathrm{a}$ & $1.695 \mathrm{ab}$ \\
\hline Média & 438 & 1.013 & 2.440 & 443 & 1.009 & 2.448 & 148 & 604 & 1.076 & 278 & 741 & 1.547 \\
\hline $\mathrm{CV}(\%)$ & 25,2 & 24,4 & 24,7 & 22,8 & 26,8 & 27,9 & 24,0 & 24,9 & 22,2 & 24,9 & 29,3 & 16,6 \\
\hline
\end{tabular}

${ }^{(1)}$ Médias seguidas de letras iguais, nas colunas, não diferem entre si pelo teste de Tukey, a 5\% de probabilidade. 
$\mathrm{O}$ acúmulo de $\mathrm{N}$ na parte aérea das forrageiras, na maturidade fisiológica do milho safrinha, foi significativamente diferente entre os tratamentos avaliados em Campos Novos Paulista e Florínea (Tabela 3). Em Palmital e Pedrinhas Paulista, não foram observadas respostas significativas para o acúmulo de nutrientes nas forrageiras, em função dos consórcios.

Em Pedrinhas Paulista, não houve diferença significativa entre os consórcios avaliados quanto ao acúmulo de nutrientes, com exceção de $\mathrm{N}$ e $\mathrm{S}$, por ocasião da maturidade fisiológica do milho (Tabela 3 ).
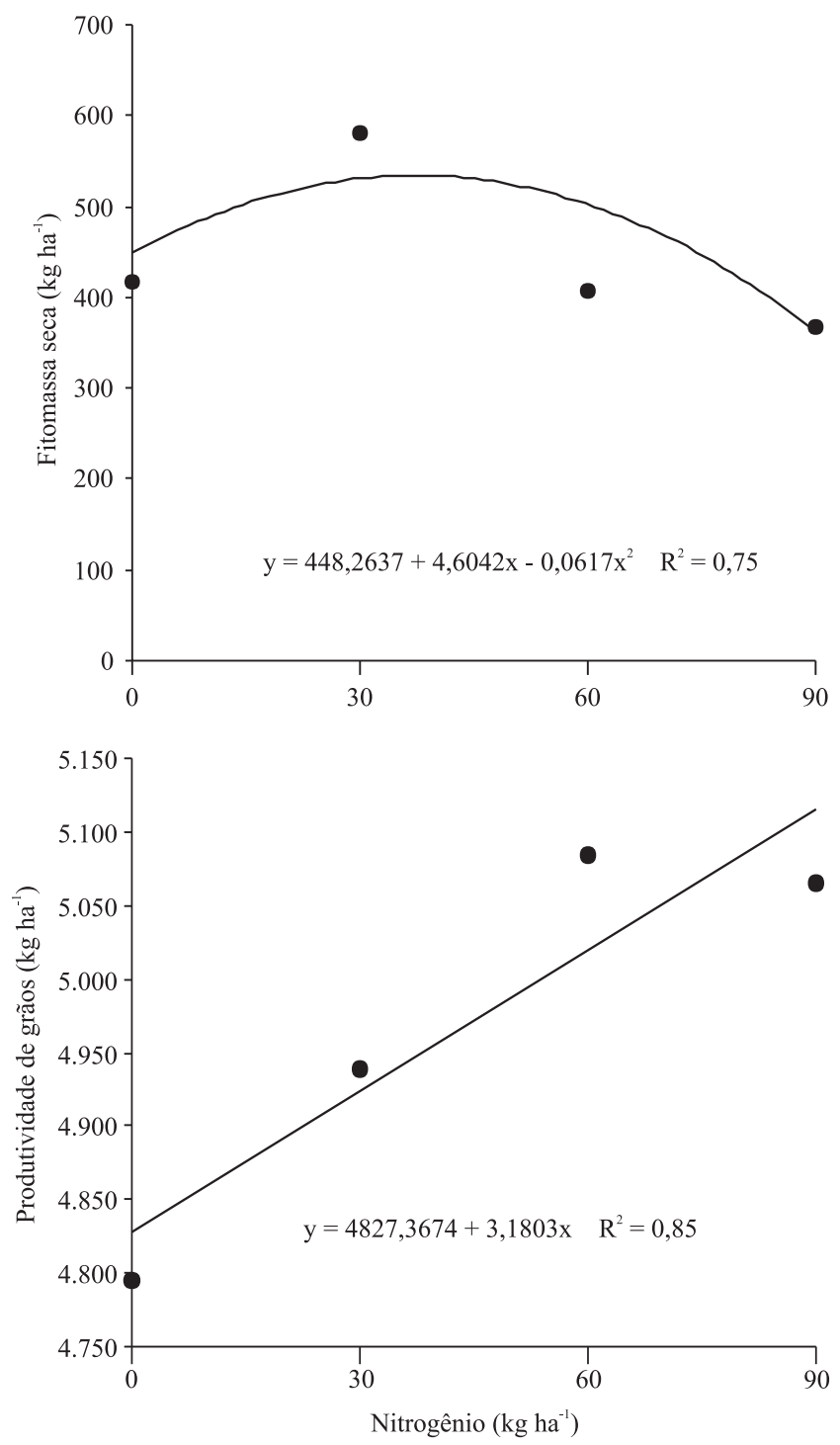

Figura 1. Massa de matéria seca de plantas forrageiras consorciadas com milho safrinha e produtividade do milho safrinha em consórcio, em função das doses de $\mathrm{N}$ aplicadas em cobertura, em Palmital.
O capim-tanzânia apresentou menor acúmulo de $\mathrm{N}$ do que o capim-marandu. Magalhães et al. (2002) obtiveram valores médios de $\mathrm{N}$ menores $\left(11,6 \mathrm{~g} \mathrm{~kg}^{-1}\right)$ do que os observados para capim-marandu, no presente trabalho. O capim-tanzânia $\left(0,8 \mathrm{~kg} \mathrm{ha}^{-1}\right)$ apresentou os menores valores de acúmulo de $\mathrm{S}$, com diferença significativa em comparação aos consórcios com capim-marandu distribuído a lanço $\left(1,3 \mathrm{~kg} \mathrm{ha}^{-1}\right) \mathrm{e}$ semeado em linha (1,2 $\left.\mathrm{kg} \mathrm{ha}^{-1}\right)$.

$\mathrm{Na}$ dessecação dos capins, antes do plantio da soja, verificou-se diferença significativa para o acúmulo de nutrientes entre os tratamentos. Em Pedrinhas Paulista foram observadas diferenças para $\mathrm{N}$ e $\mathrm{S}$, com menores valores no capimtanzânia. Em Campos Novos Paulista, o capimmarandu distribuído a lanço apresentou menores valores, em comparação aos demais tratamentos (Tabela 3). Em Palmital, foram observadas diferenças significativas entre os consórcios apenas para $\mathrm{N}$ (valor médio de $21,5 \mathrm{~kg} \mathrm{ha}^{-1}$ ) e $\mathrm{K}$ (valor médio de $36,7 \mathrm{~kg} \mathrm{ha}^{-1}$ ). Entre os tratamentos, o capim-tanzânia apresentou o maior valor para o acúmulo de $\mathrm{N}$, e o capim-marandu a lanço o menor. O capim-tanzânia também apresentou o maior valor para acúmulo de $\mathrm{K}$, com diferença significativa observada somente para o capim-marandu em linha.

Em geral, as forrageiras acumularam mais nutrientes na maturidade fisiológica do milho safrinha do que na dessecação, antes do plantio da soja. $\mathrm{O}$ aumento na proporção de folhas velhas e de colmos, por ocasião da dessecação dos capins, pode justificar o menor acúmulo de nutrientes observado nesta época, em comparação à maturidade fisiológica do milho (Tabela 3), conforme também verificado por Barducci et al. (2009).

$\mathrm{O}$ acúmulo de $\mathrm{K}$, tanto na maturidade fisiológica do milho safrinha (média dos locais de $29 \mathrm{~kg} \mathrm{ha}^{-1}$ ), como na dessecação das plantas forrageiras antes do plantio da soja $\left(19,8 \mathrm{~kg} \mathrm{ha}^{-1}\right)$, sempre foi maior em comparação aos demais nutrientes. Os acúmulos de $\mathrm{P}$ e $\mathrm{S}$ na maturidade fisiológica do milho safrinha (média dos locais de 1,5 e $1,5 \mathrm{~kg} \mathrm{ha}^{-1}$, respectivamente) e na dessecação das plantas forrageiras antes do plantio da soja (média dos locais de 1,0 e $0,7 \mathrm{~kg} \mathrm{ha}^{-1}$, respectivamente) foram os menores.

Em todos os tratamentos, a produção de matéria seca e o acúmulo de nutrientes das plantas forrageiras foram baixos, quando comparados aos resultados obtidos por Pacheco et al. (2011). Os autores relataram produção de matéria seca de $11.405 \mathrm{~kg} \mathrm{ha}^{-1}$, para $U$. brizantha, e de $6.227 \mathrm{~kg} \mathrm{ha}^{-1}$, para U. ruziziensis. Entretanto, o 
uso de plantas de cobertura pode apresentar outros benefícios além da produção de forragem, como a melhoria das condições físicas e biológicas dos solos, a minimização dos efeitos da erosão (Bertol et al., 1997) e o controle da emergência de plantas daninhas (Theisen et al., 2000). Além disso, há relatos de efeitos benéficos das plantas de cobertura nas propriedades do solo e na produtividade das culturas, decorrentes da produção de matéria seca e do acúmulo e da posterior liberação de nutrientes, pela decomposição da palhada (Torres et al., 2008).

Os consórcios de milho safrinha e plantas forrageiras não influenciaram a produtividade do milho em nenhum dos locais avaliados. Portanto, não houve competição entre as plantas forrageiras e a cultura. Com relação à adubação nitrogenada, a produtividade do milho safrinha respondeu às doses de $\mathrm{N}$ apenas em Palmital (Figura 1). Esse resultado indica que o espaçamento entre as linhas de plantio do milho e as forrageiras tem efeito significativo sobre a competição das espécies em consórcio, pois a demanda por $\mathrm{N}$ pela cultura foi maior, provavelmente, pelo menor espaçamento utilizado em Palmital. A ausência de resposta às doses de $\mathrm{N}$ nos demais locais mostra a boa capacidade de competição do milho, ao se semear a forrageira no centro da entrelinha. De acordo com Lara-Cabezas \& Pádua (2007), o milho assimila a maior parte do $\mathrm{N}$ proveniente da adubação, quando em consórcio com U. ruziziensis.

Tabela 3. Acúmulo de nutrientes $\left(\mathrm{kg} \mathrm{ha}^{-1}\right)$ na matéria seca de plantas forrageiras consorciadas com milho safrinha em Campos Novos Paulista, Florínea, Palmital e Pedrinhas Paulista, Estado de São Paulo, durante a maturidade fisiológica do milho e por ocasião da dessecação das forrageiras ${ }^{(1)}$.

\begin{tabular}{|c|c|c|c|c|c|c|c|c|c|c|c|c|}
\hline \multirow[t]{2}{*}{ Consórcio } & \multicolumn{6}{|c|}{ Maturidade fisiológica do milho } & \multicolumn{6}{|c|}{ Dessecação antes do plantio da soja } \\
\hline & $\mathrm{N}$ & $\mathrm{P}$ & $\mathrm{K}$ & $\mathrm{Ca}$ & $\mathrm{Mg}$ & $\mathrm{S}$ & $\mathrm{N}$ & $\mathrm{P}$ & $\mathrm{K}$ & $\mathrm{Ca}$ & $\mathrm{Mg}$ & $\mathrm{S}$ \\
\hline & \multicolumn{12}{|c|}{ Campos Novos Paulista } \\
\hline Capim-ruziziensis & $15,9 \mathrm{a}$ & $1,2 \mathrm{a}$ & $31,3 b$ & $6,2 \mathrm{a}$ & $3,9 \mathrm{bc}$ & $1,7 \mathrm{a}$ & $18,7 \mathrm{a}$ & $1,4 \mathrm{a}$ & $36,7 \mathrm{a}$ & $5,1 \mathrm{a}$ & $8,3 \mathrm{a}$ & $1,9 \mathrm{a}$ \\
\hline Capim-marandu & $18,1 \mathrm{a}$ & $1,3 \mathrm{a}$ & $37,4 \mathrm{ab}$ & $6,1 \mathrm{a}$ & $4,8 \mathrm{ab}$ & $1,4 \mathrm{a}$ & $15,3 \mathrm{a}$ & $1,0 \mathrm{ab}$ & $25,9 \mathrm{a}$ & $3,7 \mathrm{~b}$ & $5,0 \mathrm{a}$ & $1,1 b$ \\
\hline Capim-tanzânia & $21,1 \mathrm{a}$ & $1,5 \mathrm{a}$ & $42,1 \mathrm{a}$ & $6,3 \mathrm{a}$ & $5,5 \mathrm{a}$ & $1,6 \mathrm{a}$ & $13,4 \mathrm{a}$ & $0,9 b$ & $33,0 \mathrm{a}$ & $3,6 \mathrm{ab}$ & $6,5 \mathrm{a}$ & $1,1 \mathrm{~b}$ \\
\hline Capim-braquiária & $16,4 \mathrm{a}$ & $1,2 \mathrm{a}$ & $29,2 b$ & $5,2 \mathrm{a}$ & $3,7 b c$ & $1,5 \mathrm{a}$ & $15,0 \mathrm{a}$ & $1,1 \mathrm{ab}$ & $27,1 \mathrm{a}$ & $3,9 \mathrm{ab}$ & $6,2 \mathrm{a}$ & $1,6 \mathrm{a}$ \\
\hline Capim-marandu a lanço & $9,6 \mathrm{~b}$ & $0,6 \mathrm{~b}$ & $18,1 \mathrm{c}$ & $2,8 \mathrm{~b}$ & $2,4 \mathrm{c}$ & $0,8 \mathrm{~b}$ & $4,3 b$ & $0,3 \mathrm{c}$ & $8,3 b$ & $1,2 \mathrm{c}$ & $1,5 b$ & $0,4 \mathrm{c}$ \\
\hline Média & 16,2 & 1,2 & 31,6 & 5,3 & 4,1 & 1,4 & 13,3 & 0,9 & 26,2 & 3,5 & 5,5 & 1,2 \\
\hline \multirow[t]{2}{*}{$\mathrm{CV}(\%)$} & 48,6 & 44,8 & 48,1 & 48,4 & 45,8 & 47,1 & 47,4 & 49,9 & 53,2 & 50,5 & 52,8 & 49,9 \\
\hline & \multicolumn{12}{|c|}{ Florínea } \\
\hline Capim-ruziziensis & $13,8 \mathrm{~b}$ & $1,3 \mathrm{a}$ & $17,9 \mathrm{a}$ & $6,3 a$ & $3,3 a$ & $1,0 \mathrm{a}$ & $7,1 \mathrm{a}$ & $0,9 \mathrm{ab}$ & $10,2 \mathrm{ab}$ & $3,2 b$ & $2,5 b$ & $0,6 \mathrm{a}$ \\
\hline Capim-marandu & $14,6 b$ & $1,3 \mathrm{a}$ & $16,8 \mathrm{a}$ & $5,6 a$ & $5,2 \mathrm{a}$ & $0,9 \mathrm{a}$ & $8,3 \mathrm{a}$ & $0,9 \mathrm{ab}$ & $12,4 \mathrm{~b}$ & $3,6 \mathrm{ab}$ & $4,2 \mathrm{ab}$ & $0,7 \mathrm{a}$ \\
\hline Capim-tanzânia & $18,8 \mathrm{ab}$ & $1,7 \mathrm{a}$ & $19,0 \mathrm{a}$ & $5,8 \mathrm{a}$ & $3,7 \mathrm{a}$ & $1,2 \mathrm{a}$ & $7,7 \mathrm{a}$ & $1,0 \mathrm{ab}$ & $11,9 b$ & $4,6 \mathrm{a}$ & $4,0 \mathrm{a}$ & $0,8 \mathrm{a}$ \\
\hline Capim-braquiária & $15,2 \mathrm{ab}$ & $1,7 \mathrm{a}$ & $25,5 \mathrm{a}$ & $6,2 \mathrm{a}$ & $4,8 \mathrm{a}$ & $1,5 \mathrm{a}$ & $8,5 \mathrm{a}$ & $0,8 b$ & $9,1 \mathrm{ab}$ & $3,6 \mathrm{ab}$ & $3,9 \mathrm{ab}$ & $0,8 \mathrm{a}$ \\
\hline Capim-marandu a lanço & $21,3 \mathrm{a}$ & $1,8 \mathrm{a}$ & $14,2 \mathrm{a}$ & $6,5 \mathrm{a}$ & $2,9 \mathrm{a}$ & $1,2 \mathrm{a}$ & $9,1 \mathrm{a}$ & $1,0 \mathrm{a}$ & $8,7 \mathrm{a}$ & $5,3 \mathrm{ab}$ & $5,4 \mathrm{ab}$ & $0,8 \mathrm{a}$ \\
\hline Média & 16,7 & 1,6 & 18,7 & 6,1 & 4,0 & 1,2 & 8,1 & 0,9 & 10,5 & 4,1 & 4,0 & 0,7 \\
\hline \multirow[t]{2}{*}{ CV (\%) } & 55,5 & 51,6 & 69,6 & 60,5 & 59,8 & 53,8 & 48,4 & 49,9 & 38,2 & 53,6 & 53,6 & 45,4 \\
\hline & \multicolumn{12}{|c|}{ Palmital } \\
\hline Capim-ruziziensis & $15,3 \mathrm{a}$ & $1,3 \mathrm{a}$ & $31,9 \mathrm{a}$ & $4,9 \mathrm{a}$ & $4,8 \mathrm{a}$ & $1,6 \mathrm{a}$ & $19,2 \mathrm{ab}$ & $1,7 \mathrm{a}$ & $37,2 \mathrm{ab}$ & $5,0 \mathrm{a}$ & $6,8 \mathrm{a}$ & $1,7 \mathrm{a}$ \\
\hline Capim-marandu & $16,4 \mathrm{a}$ & $1,2 \mathrm{a}$ & $29,8 \mathrm{a}$ & $5,7 \mathrm{a}$ & $4,1 \mathrm{a}$ & $1,7 \mathrm{a}$ & $19,1 \mathrm{ab}$ & $2,1 \mathrm{a}$ & $28,1 \mathrm{a}$ & $7,1 \mathrm{a}$ & $11,7 \mathrm{a}$ & $1,5 \mathrm{a}$ \\
\hline Capim-tanzânia & $14,8 \mathrm{a}$ & $1,1 \mathrm{a}$ & $23,5 \mathrm{a}$ & $5,5 \mathrm{a}$ & $4,0 \mathrm{a}$ & $1,4 \mathrm{a}$ & $36,8 \mathrm{a}$ & $1,3 \mathrm{a}$ & $47,6 \mathrm{~b}$ & $4,8 \mathrm{a}$ & $6,9 \mathrm{a}$ & $3,0 \mathrm{a}$ \\
\hline Capim-braquiária & $16,4 \mathrm{a}$ & $1,2 \mathrm{a}$ & $33,9 \mathrm{a}$ & $6,2 \mathrm{a}$ & $4,5 \mathrm{a}$ & $1,6 \mathrm{a}$ & $19,7 \mathrm{ab}$ & $2,1 \mathrm{a}$ & $36,6 b$ & $5,1 \mathrm{a}$ & $7,4 a$ & $1,7 \mathrm{a}$ \\
\hline Capim-marandu a lanço & $13,2 \mathrm{a}$ & $1,0 \mathrm{a}$ & $32,1 \mathrm{a}$ & $4,3 \mathrm{a}$ & $3,9 \mathrm{a}$ & $1,3 \mathrm{a}$ & $12,6 \mathrm{~b}$ & $1,7 \mathrm{a}$ & $34,2 \mathrm{~b}$ & $5,8 \mathrm{a}$ & $8,0 \mathrm{a}$ & $1,0 \mathrm{a}$ \\
\hline Média & 15,2 & 1,2 & 30,2 & 5,3 & 4,3 & 1,5 & 21,5 & 1,8 & 36,7 & 5,6 & 8,2 & 1,8 \\
\hline \multirow[t]{2}{*}{$\mathrm{CV}(\%)$} & 61,3 & 61,6 & 63,3 & 174,3 & 55,4 & 174,3 & 70,7 & 73,3 & 73,4 & 70,7 & 77,8 & 74,4 \\
\hline & \multicolumn{12}{|c|}{ Pedrinhas Paulista } \\
\hline Capim-ruziziensis & $12,3 a$ & $1,3 \mathrm{a}$ & $25,2 \mathrm{a}$ & $5,4 \mathrm{a}$ & $4,1 \mathrm{a}$ & $1,1 \mathrm{a}$ & $10,7 \mathrm{ab}$ & $1,1 \mathrm{a}$ & $21,0 \mathrm{a}$ & $3,7 \mathrm{a}$ & $4,9 \mathrm{a}$ & $1,0 \mathrm{ab}$ \\
\hline Capim-marandu & $10,7 \mathrm{a}$ & $1,1 \mathrm{a}$ & $19,1 \mathrm{a}$ & $4,4 a$ & $3,5 \mathrm{a}$ & $1,0 \mathrm{a}$ & $14,1 \mathrm{a}$ & $1,2 \mathrm{a}$ & $26,2 \mathrm{a}$ & $4,8 \mathrm{a}$ & $5,8 \mathrm{a}$ & $1,2 \mathrm{a}$ \\
\hline Capim-tanzânia & $10,3 \mathrm{a}$ & $0,9 \mathrm{a}$ & $20,2 \mathrm{a}$ & $4,5 \mathrm{a}$ & $3,5 \mathrm{a}$ & $0,9 \mathrm{a}$ & $9,4 b$ & $0,9 a$ & $19,8 \mathrm{a}$ & $3,2 \mathrm{a}$ & $4,2 \mathrm{a}$ & $0,8 b$ \\
\hline Capim-braquiária & $10,5 \mathrm{a}$ & $1,1 \mathrm{a}$ & $20,4 a$ & $5,1 \mathrm{a}$ & $4,1 \mathrm{a}$ & $1,0 \mathrm{a}$ & $11,0 \mathrm{ab}$ & $1,2 \mathrm{a}$ & $21,2 \mathrm{a}$ & $3,7 \mathrm{a}$ & $4,6 a$ & $1,0 \mathrm{ab}$ \\
\hline Capim-marandu a lanço & $13,0 \mathrm{a}$ & $1,1 \mathrm{a}$ & $25,6 \mathrm{a}$ & $5,3 \mathrm{a}$ & $4,5 \mathrm{a}$ & $1,1 \mathrm{a}$ & $13,2 \mathrm{ab}$ & $1,2 \mathrm{a}$ & $25,1 \mathrm{a}$ & $4,7 \mathrm{a}$ & $5,7 \mathrm{a}$ & $1,3 \mathrm{a}$ \\
\hline Média & 11,4 & 1,1 & 22,1 & 4,9 & 3,9 & 1,0 & 11,7 & 1,1 & 22,7 & 4,0 & 5,0 & 1,1 \\
\hline CV (\%) & 62,3 & 57,6 & 59,0 & 62,1 & 71,9 & 56,8 & 57,9 & 56,2 & 54,5 & 60,5 & 69,8 & 53,4 \\
\hline
\end{tabular}

${ }^{(1)}$ Médias seguidas de letras iguais, nas colunas, não diferem entre si pelo teste de Tukey, a 5\% de probabilidade. 


\section{Conclusões}

1. O maior acúmulo de matéria seca das forrageiras ocorre após a colheita do milho safrinha.

2. O consórcio com plantas forrageiras não afeta a produtividade de grãos de milho safrinha, em semeadura tardia.

3. Quando as forrageiras são semeadas no centro da entrelinha do milho, a adubação nitrogenada em cobertura não interfere na produção de matéria seca nem no acúmulo de nutrientes pelas forrageiras.

\section{Agradecimentos}

À Fundação de Amparo à Pesquisa do Estado de São Paulo, pelo apoio financeiro.

\section{Referências}

BARDUCCI, R.S.; COSTA, C.; CRUSCIOL, C.A.C.; BORGHI, É.; PUTAROV, T.C.; SARTI, L.M.N. Produção de Brachiaria brizantha e Panicum maximum com milho e adubação nitrogenada. Archivos de Zootecnia, v.58, p.211-222, 2009.

BATAGLIA, O.C.; TEIXEIRA, J.P.F.; FURLANI, A.M.C.; GALLO, J.R. Métodos de análise química de plantas. Campinas: Instituto Agronômico, 1978. 31p. (IAC. Circular, 87).

BERTOL, I.; COGO, N.P.; LEVIEN, R. Erosão hídrica em diferentes preparos do solo logo após as colheitas de milho e trigo, na presença e na ausência dos resíduos culturais. Revista Brasileira de Ciência do Solo, v.21, p.409-418, 1997.

BOER, C.A.; ASSIS, R.L. de; SILVA, G.P.; BRAZ, A.J.B.P.; BARROSO, A.L. de L.; CARRGNELUTTI FILHO, A.; PIRES, F.R. Ciclagem de nutrientes por plantas de cobertura na entressafra em um solo de cerrado. Pesquisa Agropecuária Brasileira, v.42, p.1269-1276, 2007.

BORGHI, É.; CRUCIOL, C.A.C. Produtividade de milho, espaçamento e modalidade de consorciação com Brachiaria brizantha em sistema plantio direto. Pesquisa Agropecuária Brasileira, v.42, p.163-171, 2007.

BORGHI, É.; MOBRICCI, C.; PULZ, A.L.; ONO, E.O.; CRUCIOL, C.A.C. Crescimento de Brachiaria brizantha em cultivo consorciado com milho em sistema de plantio direto. Acta Scientiarum. Agronomy, v.29, p.91-98, 2007.

BROCH, D.L.; BARROS, R.; RANNO, S.K. Consórcio milho safrinha/pastagem. In: TECNOLOGIA e produção: milho safrinha e culturas de inverno 2008. 4.ed. Maracajú: Fundação MS, 2007. p.15-29.

BRUNINI, O.; PRELA, A. O clima na região do Médio Paranapanema. In: DUARTE, A.P. (Ed.). Duas décadas da estação experimental de Agronomia-Apta Médio Paranapanema: histórico, presente e perspectivas. Campinas: Instituto Agronômico, 2007. p.29-38.

CECCON, G. Milho safrinha com solo protegido e retorno econômico em Mato Grosso do Sul. Revista Plantio Direto, v.97, p.17-20, 2007.

CHAPMAN, D.F.; LAMAIRE, G. Morphogenetic and structural determinants of plant regrowth after defoliation. In: INTERNATIONAL GRASSLAND CONGRESS, 17., 1993, Palmerston North. Proceedings. Palmerston North: New Zealand Grassland Association, 1993. p.95-104.

DUARTE, A.P.; CANTARELlA, H. Adubação em sistemas de produção de soja e milho safrinha. In: SEMINÁRIO NACIONAL DO MILHO SAFRINHA: RUMO A ESTABILIDADE, 9., 2007, Dourados, 2007. Anais. Dourados: Embrapa Agropecuária Oeste, 2007. p.44-61. (Embrapa Agropecuária Oeste. Documentos, 89).

HODGSON, J. Grazing management: science into practice. Hong Kong: Longman, 1990. 203p.

KLUTHCOUSKI, J.; AIDAR, H. Sistema Santa Fé. In: KLUTHCOUSKI, J.; STONE, L.F.; AIDAR, H. (Ed.) Integração lavoura-pecuária. Santo Antônio de Goiás: Embrapa Arroz e Feijão, 2003. p.405-441.

LARA-CABEZAS, W.A.R.; PÁDUA, R.V. de. Eficiência e distribuição de nitrogênio aplicado em cobertura na cultura de milho consorciada com Brachiaria ruziziensis, cultivada no sistema santa fé. Bragantia, v.66, p.131-140, 2007.

MAGALHÃES, R.T. de; OLIVEIRA, I.P. de; KLIEMANN, H.J. Relações da produção de massa seca e as quantidades de nutrientes exportados por Brachiaria brizantha em solos sob o manejo pelo sistema "Barreirão". Pesquisa Agropecuária Tropical, v.32, p.13-20, 2002.

PACHECO, L.P.; LEANDRO, W.M.; MACHADO, P.L.O. de A.; ASSIS, R.L.; COBUCCI, T.; MADARI, B.E.; PETTER, F.A. Produção de fitomassa e acúmulo e liberação de nutrientes por plantas de cobertura na safrinha. Pesquisa Agropecuária Brasileira, v.46, p.17-25, 2011.

SANTOS, H.G. dos; JACOMINE, P.K.T.; ANJOS, L.H.C. dos; OLIVEIRA, V.A. de; OLIVEIRA, J.B. de; COELHO, M.R.; LUMBRERAS, J.F.; CUNHA, T.J.F. (Ed.). Sistema brasileiro de classificação de solos. 2.ed. Rio de Janeiro: Embrapa Solos, 2006. $306 \mathrm{p}$.

SAS INSTITUTE. SAS system for windows: release 6.08. Cary: SAS Institute, 1996.

THEISEN, G.; VIDAL, R.A.; FLECK, N.G. Redução da infestação de Brachiaria Plantaginea em soja pela cobertura do solo com palha de aveia preta. Pesquisa Agropecuária brasileira, v.35, p.753-756, 2000.

TORRES, J.L.R.; PEREIRA, M.G.; FABIAN, A.J. Produção de fitomassa por plantas de cobertura e mineralização de seus resíduos em plantio direto. Pesquisa Agropecuária Brasileira, v.43, p.421-428, 2008.

Recebido em 30 de julho de 2010 e aprovado em 30 de setembro de 2011

Pesq. agropec. bras., Brasília, v.46, n.10, p.1154-1160, out. 2011 